\title{
Perancangan Sistem Informasi Pembayaran Administrasi SMK Negeri 1 Jiwan
}

\author{
Ridho Pamungkas \\ Sistem Informasi Universitas PGRI Madiun \\ Madiun, Indonesia \\ E-mail: ridho.pamungkas@unipma.ac.id
}

Abstract-Perkembangan teknologi yang begitu cepat menuntut sekolah untuk memberikan pelayanan yang optimal kepada siswanya khususnya di SMK Negeri 1 Jiwan. Meningkatkan kualitas sistem informasi merupakan salah satu cara untuk mendukung pelayanan terhadap siswa. Sistem informasi pembayaran administrasi dirancang sesuai dengan keadaan di sekolah. Pengumpulan data dilakukan dengan menggunakan metode interview dan Metode observasi. Penelitian ini menghasilkan perancangan sistem informasi menggunakan Microsoft Visual basic 6.0 yang dapat membantu SMK Negeri 1 Jiwan untuk memberi pelayanan dalam pembayaran administrasi siswanya.

Kata kunci : Sistem Informasi, pembayaran administrasi, SMK Negeri 1 Jiwan.

\section{PENDAHULUAN}

Meskipun penerapan teknologi informasi terus berkembang, akan tetapi pada kenyataannya masih terdapat instansi - instansi yang belum tersentuh dengan adanya teknologi informasi itu sendiri, seperti halnya pembayaran Administrasi siswa di SMK Negeri 1 Jiwan masih menggunakan proses pencatatan untuk menangani proses pembayaran Administrasi siswa, sehingga timbul suatu permasalahan dalam hal keefektifan dan efisiensi pengelolaan data menjadi sebuah informasi dalam proses manajemen sekolah. Karena dalam lingkungan pendidikan, pemanfaatan teknologi informasi sangat penting, dan harus dapat digunakan untuk berbagai keperluan.

Pada dasarnya sebuah lembaga maupun organisasi yang memanfaatkan teknologi informasi secara optimal yang dapat bertahan dalam era global ini, karena lewat pemanfaatan teknologi informasi sebuah lembaga atau organisasi dapat mengaskses informasi dengan cepat, tepat dan akurat serta dapat memberikan pelayanan yang efektif dan efisien. Seiring dengan terus bertambahnya jumlah siswa pada SMK Negeri 1 Jiwan Kabupaten Madiun menuntut lembaga sekolah untuk bisa memberikan pelayanan terbaik bagi siswa dalam pemanfaatan sarana maupun prasarana pendukung proses pembelajaran. 
Dari beberapa hal tersebut dapat dilihat mengenai perlunya pembangunan sebuah sistem informasi khususnya sistem informasi administrasi siswa untuk diterapkan dalam proses pengolahan data administrasi siswa. Pada rencana perancangan Sistem Informasi Pembayaran Administrasi Siswa hendaknya sistem yang direncanakan akan mampu menyelesaikan permasalahan menyangkut sistem pembayaran administrasi siswa di SMK Negeri 1 Jiwan Kabupaten Madiun.

\section{METODE PENELITIAN}

- Konsep Dasar Sistem Informasi

- Sistem

Konsep dasar sistem ada dua pendekatan yaitu penekanan pada prosedurnya dan penekanan pada komponennya atau elemen.

Pendekatan pertama adalah pendekatan sistem yang lebih menekankan pada prosedurnya didefinisikan oleh Jerry Fitzgerald, yang mendefinisikan suatu sistem adalah suatu jaringan kerja dari prosedur-prosedur yang saling berhubungan, berkumpul bersama-sama untuk melakukan suatu kegiatan atau untuk menyelesaikan suatu sasaran yang tertentu[1].

Pendekatan kedua adalah pendekatan sistem yang lebih menekankan pada komponen atau elemennya, mendefinisikan suatu sistem adalah kumpulan dari elemen-elemen yang berinteraksi untuk mencapai suatu tujuan tertentu.

- Informasi

Informasi adalah data yang telah diolah menjadi bentuk lain yang lebih berguna atau bernilai bagi yang pemakai dan dapat dijadikan sebagai bahan dalam pengambilan keputusan. Sumber dari informasi adalah data. Data adalah kenyataan yang menggambarkan suatu kejadian-kejadian dan kesatuan kenyataan. Data merupakan bentuk yang masih mentah sehingga perlu diolah lebih lanjut agar mempunyai nilai atau kegunaan bagi pemakainya. Kualitas informasi tergantung pada beberapa hal yaitu:

- Akurat, berati informasi harus bebas dari kesalahan-kesalahan.

- Tepat waktu, informasi yang diterima harus tepat pada waktunya.

- Relevan, informasi harus mempunyai manfaat bagi penerima. 
Jurnal INTENSIF, Vol.1 No.2 Agustus 2017

ISSN: 2580-409X (Cetak) / 2549-6824 (Online)

- Sistem Informasi

Informasi merupakan hal yang sangat penting di dalam pengambilan sebuah keputusan. Informasi dapat diperoleh dari sistem informasi (information systems). sistem informasi adalah suatu sistem di dalam suatu organisasi yang mempertemukan kebutuhan pengolahan transaksi harian, mendukung operasi, bersifat manajerial dan kegiatan strategi dari suatu organisasi dan menyediakan pihak luar tertentu dengan laporan-laporan yang diperlukan.[2]

- Konsep Dasar Administrasi Pembayaran Siswa

Administrasi adalah rangkaian kegiatan yang berupa proses pengendalian usaha kerja sama sekelompok manusia untuk mencapai tujuan bersama yang telah ditetapka sebelumnya. [3] dan administrasi pembayaran siswa merupakan suatu kegiatan administrasi yang melayani semua pembayaran siswa baik di lembaga pendidikan formal maupun non formal agar berlangsung secara efektif dan efisien dalam mencapai tujuannya.

- Model Pengembangan perangkat lunak

Penelitian ini menggunakan proses Waterfall Model sebagai pola pengembangan sistem. Definisi yang diartikan oleh Roger S. Pressman dalam bukunya Software Engineering : Seventh Edition dijelaskan bahwa : "Waterfall Model sebuah proses perancangan yang secara berurutan dan sering digunakan dalam proses pengembangan perangkat lunak.” Menurut Pressman Waterfall Model adalah model klasik yang bersifat sistematis, berurutan dalam membangun software.[4] Berikut ini gambaran dari Waterfall Model.

Fase-fase dalam Waterfall Model menurut Pressman :

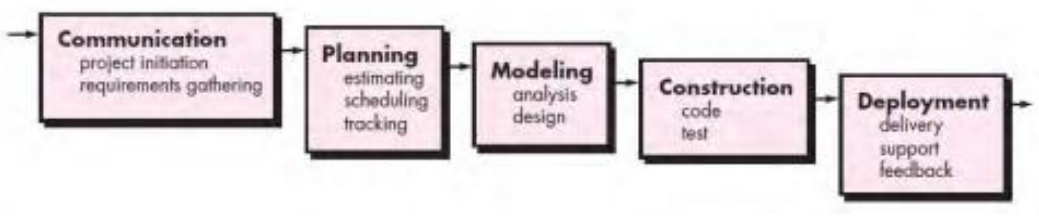

\section{Gambar 1. WATERFALL MODEL}

Berikut adalah gambar pengembangan perangkat lunak berurutan/ linear :

- Communication

Langkah ini merupakan analisis terhadap kebutuhan software, dan tahap untuk mengadakan pengumpulan data dengan melakukan pertemuan dengan customer, maupun mengumpulkan data-data tambahan baik yang ada di jurnal, artikel, maupun dari internet.

- Planning

Proses planning merupakan lanjutan dari proses communication (analysis requirement). Tahapan ini akan menghasilkan dokumen user requirement atau bisa dikatakan sebagai data yang 
berhubungan dengan keinginan user dalam pembuatan software, termasuk rencana yang akan dilakukan.

- Modeling

Proses modeling ini akan menerjemahkan syarat kebutuhan ke sebuah perancangan software yang dapat diperkirakan sebelum dibuat coding. Proses ini berfokus pada rancangan struktur data, arsitektur software, representasi interface, dan detail (algoritma) prosedural. Tahapan ini akan menghasilkan dokumen yang disebut software requirement.

- Construction

Construction merupakan proses membuat kode. Coding atau pengkodean merupakan penerjemahan desain dalam bahasa yang bisa dikenali oleh komputer. Programmer akan menerjemahkan transaksi yang diminta oleh user. Tahapan inilah yang merupakan tahapan secara nyata dalam mengerjakan suatu software, artinya penggunaan komputer akan dimaksimalkan dalam tahapan ini. Setelah pengkodean selesai maka akan dilakukan testing terhadap sistem yang telah dibuat tadi. Tujuan testing adalah menemukan kesalahan-kesalahan terhadap sistem tersebut untuk kemudian bisa diperbaiki.

- Deployment

Tahapan ini bisa dikatakan final dalam pembuatan sebuah software atau sistem. Setelah melakukan analisis, desain dan pengkodean maka sistem yang sudah jadi akan digunakan oleh user. Kemudian software yang telah dibuat harus dilakukan pemeliharaan secara berkala.

\section{HASIL DAN PEMBAHASAN}

- Flow Chart Sistem Informasi Pembayaran Administrasi Siswa

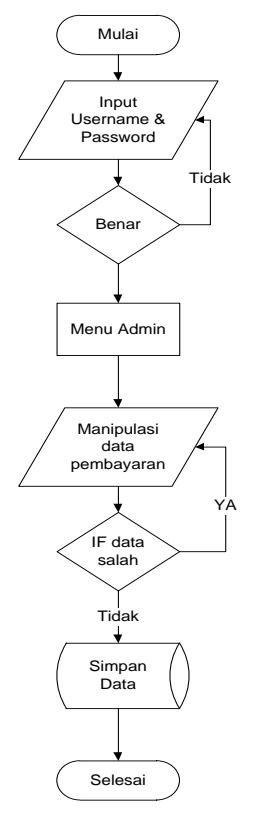

Gambar 2. FLOW CHART APLIKASI SISTEM INFORMASI PEMBAYARAN SISWA 
- Perancangan Database

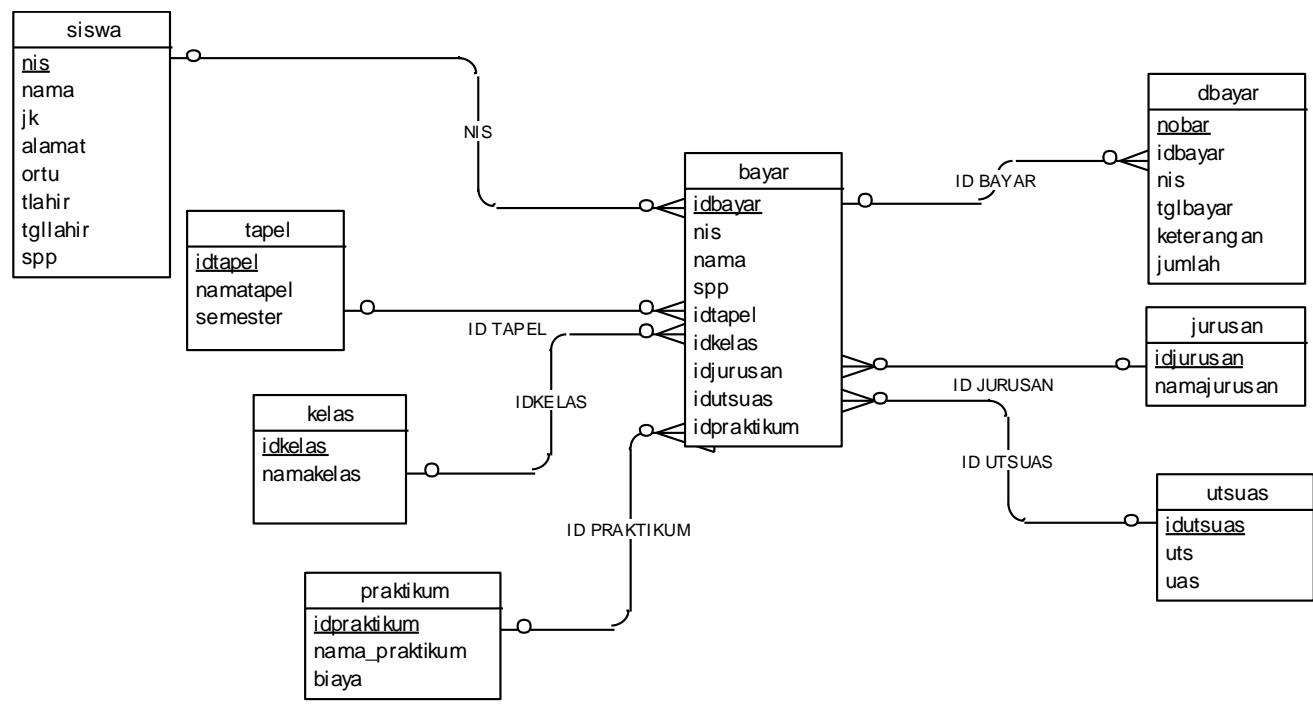

Gambar 3. RELASI DATA BASE

- Data Flow Diagram

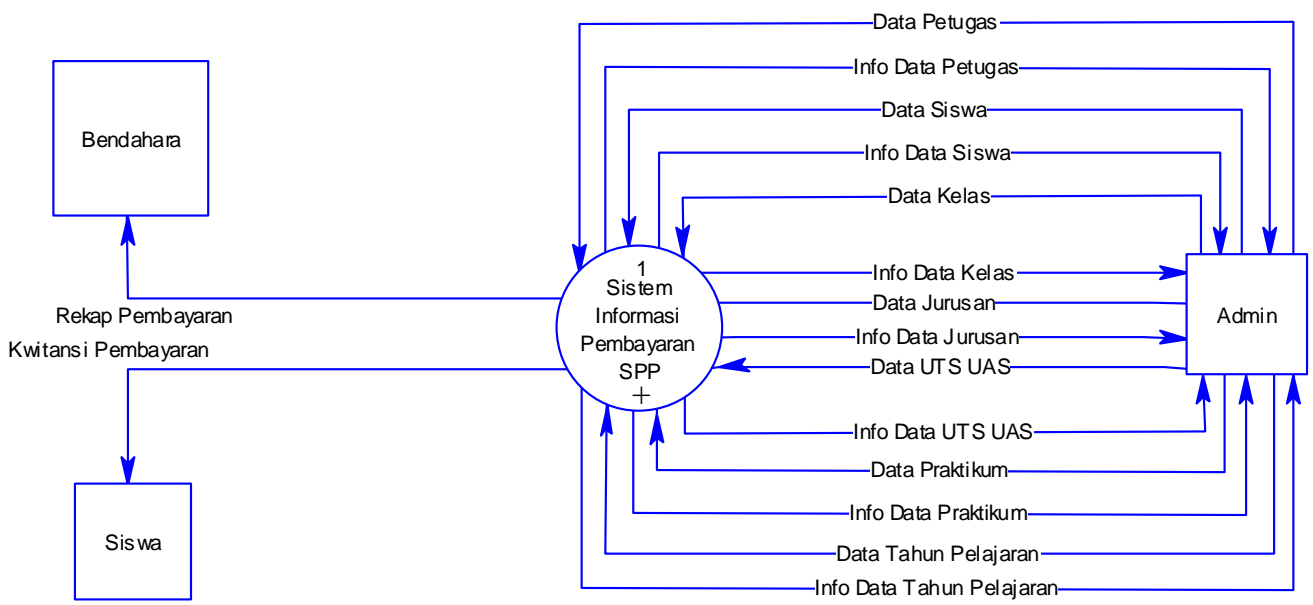

Gambar 4. DIAGRAM KONTEKS 


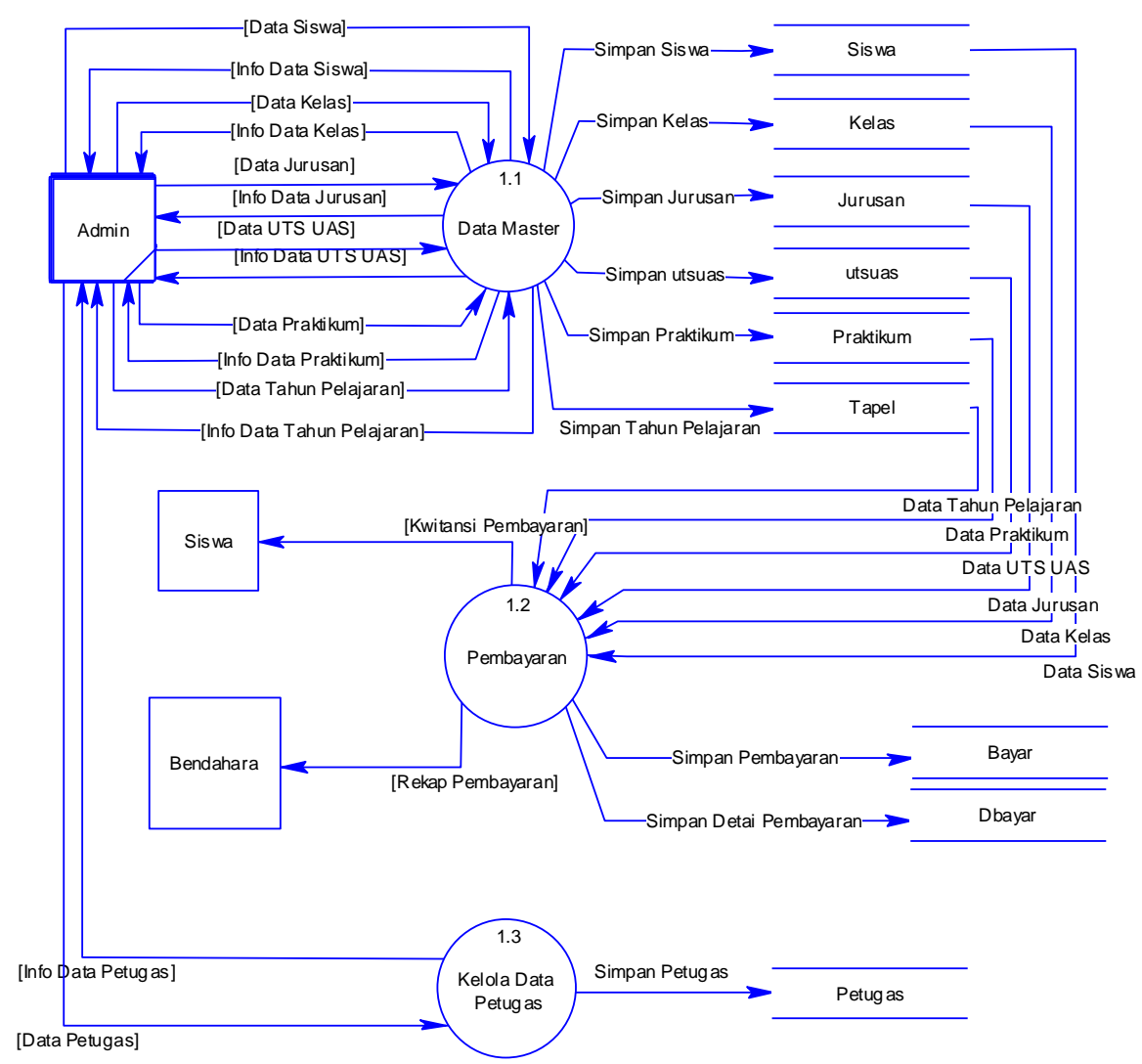

Gambar 5. DATA Flow DiAgRAM LEVEL 1

- Implementasi Sistem

- Form Login

Pada form login ini operator harus memasukkan username dan password yang benar untuk dapat masuk ke menu utama sistem. Setelah operator memasukkan username dan password yang benar kemudian klik tombol masuk. Untuk keluar dari sistem tekan tombol Batal. Tampilan form login dapat dilihat pada gambar berikut ini.

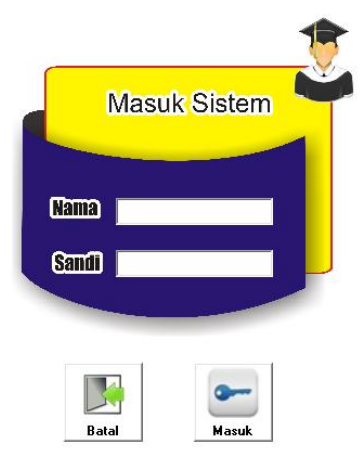

Gambar 6. FORM LOGIN 
- Form Menu Utama

Terdapat 5 menu pada form menu utama yaitu master (form siswa,form kelas, form jurusan, form tahun ajaran, form uts/uas dan form praktikum), pembayaran, laporan, Petugas dan exit/keluar sistem.

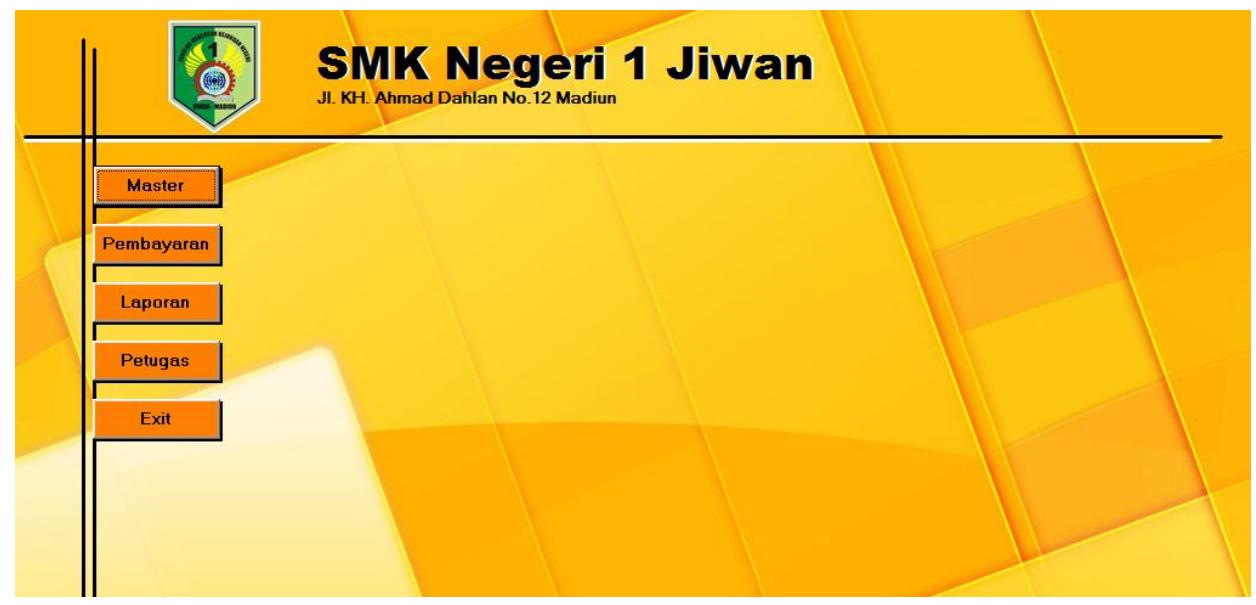

Gambar 7. FORM MENU UTAMA

- Form Pembayaran

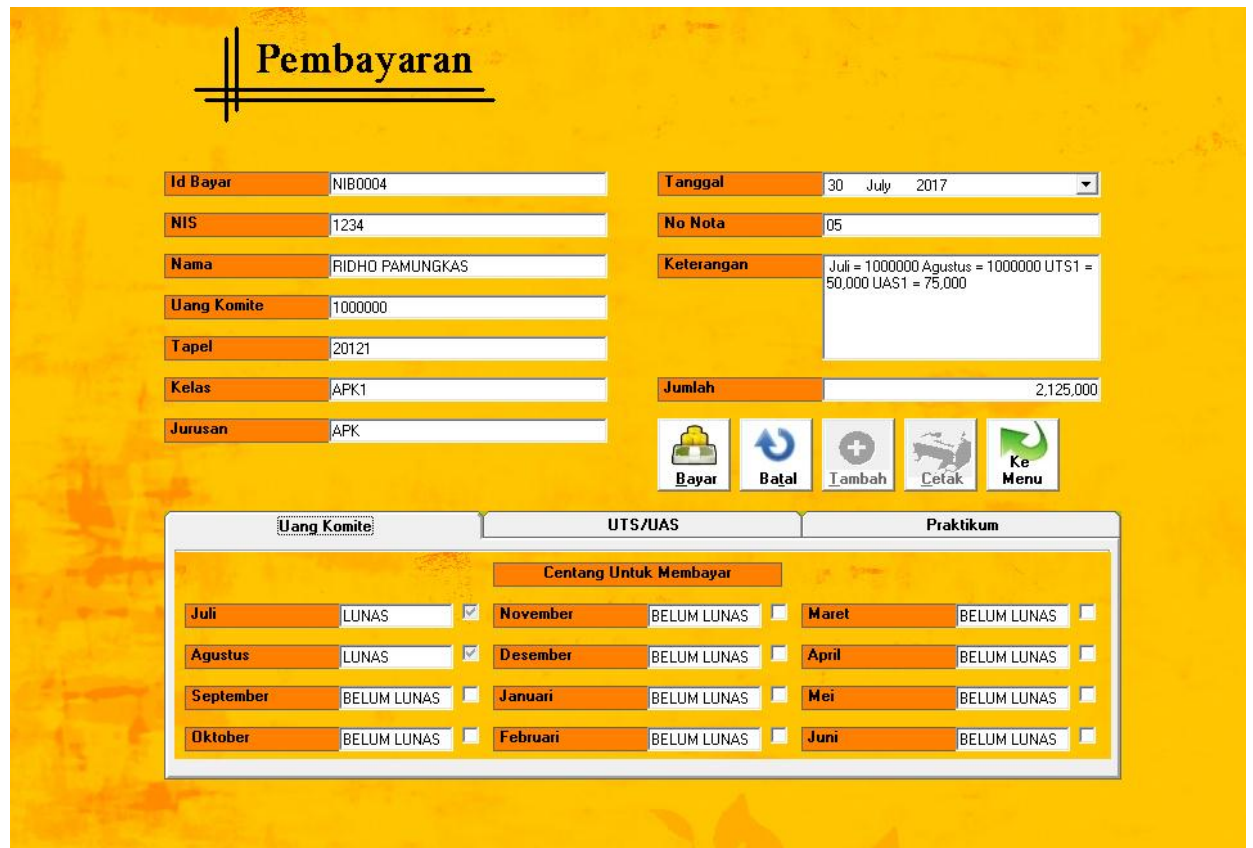

Gambar 8. FORM PEMBAYARAN 


\section{KESIMPULAN DAN SARAN}

Dari hasil uji coba sistem yang dibangun dapat mempercepat dalam pencarian dan pengelolaan data-data laporan pembayaran administrasi siswa sehingga kinerja sistem lebih efektif dan akurat. Perangkat lunak sistem informasi pembayaran administrasi ini masih dapat di kembangkan seiring dengan perkembangannya dan kebutuhan pengguna sistem sehingga dapat mencapai hasil dan kinerja sistem yang lebih baik.

\section{DAfTAR Pustaka}

[1] J. F. Gerald, A. F. Gerald, and Warren D. Stalling, Fundamentals Of System Analysis (2nd edition). New York: John Walley \& Sons, 1981.

[2] K. Kendall, Analisis dan Perancangan Sistem. Jakarta: PT Prenhallindo, 2003.

[3] Nawawi and Hadari, Administrasi Pendidikan. Jakarta: CV. Haji Masagung, 1994.I

[4] R. S. Pressman, Software Enggineering: A Practitioner's Approach (7th Edition). New York: McGraw-Hill, 2010. 